\title{
FRANQUEZA, FILOSOFIA E EDUCAÇÃO: ESTÉTICA DA EXISTÊNCIA E PARRHESÍA A PARTIR DO SERIADO THE GOOD DOCTOR
}

\author{
FRANKNESS, PHILOSOPHY AND EDUCATION: \\ AESTHETICS OF EXISTENCE AND PARRHESIA \\ FROM THE SERIES THE GOOD DOCTOR
}

\begin{abstract}
FRANQUEZA, FILOSOFÍA E EDUCACIÓN: ESTÉTICA DE LA EXISTENCIA Y PARRESIA DE LA SERIE EL DOCTOR BUENO
\end{abstract}

\author{
FERNANDA ANTÔNIA BARbOSA DA MOTA ${ }^{\mathrm{I}}$ \\ Heraldo Aparecido Silva ${ }^{I I}$ \\ IUniversidade Federal do Piauí (UFPI), Teresina/PI-Brasil \\ IIUniversidade Federal do Piauí (UFPI), Teresina/PI-Brasil
}

RESUMo O propósito deste trabalho é apresentar algumas reflexões sobre o seriado The Good Doctor a partir de conceitos filosóficos de Michel Foucault. Inicialmente, o estudo descreve as linhas gerais do seriado dramático. Em seguida, exibe as noções teóricas foucaultianas de estética da existência e parrhesía. Posteriormente, é estabelecida a articulação entre alguns tópicos da referida série e os conceitos foucaultianos que servem de aporte teórico analítico. Os principais aportes teóricos são extraídos de autores como: Muchail (2004; 2011), Veiga-Neto (2011), (GALLO, 2012), Foucault (2004; 2006; 2012; 2013), entre outros. O resultado da discussão evidencia que o uso de dispositivos culturais não teóricos, como o seriado televisivo neste caso, constitui um recurso interessante como introdução à discussão de alguns temas relacionados aos campos investigativos da filosofia e da educação.

Palavras-chave: Filosofia da EducaÇão; Seriados televisivos; Estética da existênCIA; PARRHESÍA.

Abstract The purpose of this work is to present some reflections on the series The Good Doctor from Michel Foucault's philosophical concepts. Initially, the study describes the broad lines of the dramatic series. Then, it present's Foucault's theoretical notions of aesthetics of existence and parrhesia. Subsequently, it is established the articulation between 
some topics of the referred series and the Foucaltian concepts that serve as analytical theoretical support. The main theoretical contributions are extracted from authors such as: Muchail (2004; 2011), Veiga-Neto (2011), (GALLO, 2012), Foucault (2004; 2006; 2012; 2013), among others. The result of discussion shows that the use of non-theoretical cultural devices, such as the television series in the present case, constitutes an interesting resource as an introduction to the discussion of some themes related to the investigative fields of philosophy and education.

Keywords: Philosophy of Education; Television SERIES; Aesthetics of existence; PARRHESÍA.

RESUMEN El propósito de este artículo es presentear algunas reflexiones sobre la serie The Good Doctor basado em los conceptos filosóficos de Michel Foucault. Inicialmente, el estudio describe las líneas generales de la série dramática. Luego, presenta las nociones teóricas de Foucault sobre la estética de la existência y la parrhesia. Posteriormente, se establece la articulación entre algunos temas de la serie referida y los conceptos foucaultianos que sirven de soporte teórico analítico. Las principales contribuiciones teóricas se extraem de autores como: Muchail (2004; 2011), Veiga-Neto (2011), (GALLO, 2012), Foucault (2004; 2006; 2012; 2013), entre otros. O resultado de la discusión muestra que el uso de dispositivos culturales no teóricos, como la serie de televisón en el presente caso, constituye um recurso interessante como introducción a la discusión de algunos temas relacionados com los campos de investigación de la filosofia y la educación.

Palabras Clave: Filosofía de la educación; Series de televisión; Estética de la EXISTÊNCIA; PARRHESÍA.

\section{INTRODUÇÃO}

O seriado dramático The Good Doctor (O Bom Doutor, EUA, 2017-) possui atualmente três temporadas, totalizando 46 episódios, transmitidos para o Reino Unido, Irlanda, Austrália, Japão, Holanda, Portugal e Espanha. No Brasil, o referido seriado já foi exibido pela TV aberta na Rede Globo e atualmente pode ser encontrado no canal pago GNT e na plataforma de streaming Globoplay. A primeira temporada tem 18 episódios e foi exibida originalmente, em 2017; a segunda temporada também tem o mesmo número de episódios e estreou no ano de 2018; a terceira temporada tem 10 episódios lançados em 2019. Essa produção norte-americana da rede American Broadcasting Company (ABC) e Sony Pictures Television (SPT) foi baseada numa série televisiva da Coreia do Sul, do ano de 2013, também denominada The Good Doctor (IMDB, 2019). Um dos principais produtores executivos da série é David Shore, responsável pelo longevo seriado House, M. D., que também é um drama médico.

O protagonista do seriado é o fictício jovem médico Shaun Murphy, cuja principal peculiaridade é a sua condição de autista, portador da Síndrome de Savant. Em linhas gerais, considera-se que: "A Síndrome de Savant é uma condição rara, em que a pessoa portadora das mais várias desordens mentais, incluindo o autismo, apresenta brilhante talento ou habilidade contrastando com suas limitações" (SIQUEIRA, et al., 2019, p. 1). Assim, o 
seriado enfoca principalmente as dificuldades vivenciadas pelo protagonista em relação ao convívio social e profissional com outras pessoas.

Em linhas gerais, os Transtornos do Espectro Autista (TEA) são caracterizados como transtornos do neurodesenvolvimento e, caracteristicamente, geram efeitos diferentes nos indivíduos que têm problemas para desenvolver suas habilidades nos aspectos cognitivo, comportamental, comunicacional, social e linguístico.

\footnotetext{
Classificados como transtornos do espectro autista ou transtornos globais do desenvolvimento, esses problemas de origem neuropsicológica se manifestam na infância e, com maior ou menor intensidade, prejudicam por toda a vida a capacidade de seus portadores se comunicarem e se relacionarem com outras pessoas. Incluem quadros variados como o autismo clássico, marcado por dificuldades severas de linguagem e de interação social; a síndrome de Asperger, na qual a inteligência é normal ou superior à média e a aquisição da linguagem se dá sem problemas, mas em que são comuns os gestos repetitivos e a falta de controle em movimentos delicados; ou ainda a síndrome de savant, em que, apesar do retardo mental, a memória ou as habilidades matemáticas ou artísticas são extraordinárias (ZORZETTO, 2011, p. 17).
}

A aprendizagem de habilidades necessárias para as interações sociais é mais complexa porque demanda a compreensão de expressões faciais, sons, falas e gestos corporais que, não obstante, são considerados problemáticos visto que: “[...] as crianças com autismo consideram a interação com objetos mais interessante e a interação com as pessoas menos interessante, ao contrário das outras crianças" (ROGERS; DAWSON; VISMARA, 2015, p. 58). Nas crianças autistas, é considerado comum o contraste entre um desempenho alto em algumas áreas e a apresentação de atrasos significativos em habilidades para a comunicação verbal e não-verbal, necessárias para a interação social em contextos distintos. Desse modo, “[...] o termo para esses picos e vales nos marcos de desenvolvimento-padrão é "habilidades dispersas". As crianças recebem diagnósticos do espectro autista quando suas habilidades, em vez de se alinharem organizadamente, se espalham por todo o mapa de desenvolvimento" (BARNETT, 2013, p. 36).

Em decorrência da delimitação temática do presente estudo, enfatizaremos alguns aspectos da descrição da Síndrome de Savant, pelo fato de a mesma estar diretamente relacionada ao protagonista do seriado analisado. Assim, a principal chave interpretativa que utilizaremos no decorrer do artigo para analisar alguns aspectos da primeira temporada do seriado reside na possibilidade de compreender a vida do protagonista a partir de duas noções teóricas principais, a estética da existência e a parrhesía, extraídas do legado tardio do filósofo francês Michel Foucault.

\section{A ESTÉTICA DA EXISTÊNCIA}

A noção de estética da existência está relacionada ao derradeiro movimento que Foucault faz no contexto de seu legado intelectual, constituído por elementos teóricos que, embora elaborados em momento distintos, se complementam (MUCHAIL, 2004; 2011). Por isso, embora seja possível diferenciar três ênfases conceituais distintas no pensamento 
foucaultiano, respectivamente, denominados de arqueologia do saber, genealogia do poder e estética da existência, não é correto supor que as mesmas sejam apartadas entre si (VEIGA-NETO, 2011). Trata-se apenas de mudanças de perspectivas ou, conforme elucida o próprio filósofo francês, de aspectos complementares de uma investigação sobre o mesmo problema: "[...] isto é, as relações entre o sujeito, a verdade e a constituição da experiência" (FOUCAULT, 2012a, p. 282).

Dessa forma, no contexto do legado teórico foucaultiano, temos a identificação de quatro grupos de tecnologias que permeiam as relações entre o sujeito e as práticas discursivas de saberes, as práticas de poder e as práticas de si. No âmbito da estética da existência, tais tecnologias são caracterizadas do seguinte modo:

\footnotetext{
Como contexto, devemos entender que há quatro grupos principais de "tecnologias": cada um deles uma matriz de razão prática: [1] tecnologias de produção, que permitem produzir, transformar ou manipular as coisas; [2] tecnologias dos sistemas de signos, que permitem utilizar signos, sentidos, símbolos ou significação; [3] tecnologias de poder, que determinam a conduta dos indivíduos e os submetem a certos fins ou dominação, objetivando o sujeito; [4] tecnologias de si, que permitem aos indivíduos efetuar, com seus próprios meios ou com a ajuda de outros, um certo número de operações em seus próprios corpos, almas, pensamentos, conduta e modo de ser, de modo a transformá-los com o objetivo de alcançar um certo estado de felicidade, pureza, sabedoria, perfeição ou imortalidade (FOUCAULT, 2004, p. 324).
}

Nessa perspectiva, é importante ressaltar que na concepção foucaultiana “[...] o sujeito se constitui através de práticas de sujeição ou, de maneira mais autônoma, através de práticas de liberação, de liberdade, como na Antiguidade - a partir, obviamente, de um certo número de regras, de estilos, de convenções que podemos encontrar no meio cultural" (FOUCAULT, 2012a, p. 284). Como excede o escopo do presente texto abordar as quatro modalidades de tecnologias, delimitaremos esta discussão ao tópico das tecnologias de si, visto que se trata de um tema central no âmbito da estética da existência foucaultiana.

As tecnologias de si ou práticas de si designam as operações que o sujeito efetua em si mesmo para fins de autotransformação. Estudar, ler, meditar, escrever, examinar a si mesmo, cultivar o silêncio e a arte da escuta constituem uma preparação tanto para a vida quanto para a morte. Para os filósofos gregos antigos, o autoconhecimento e o cuidado de si dependiam diretamente do cultivo de tais práticas (FOUCAULT, 2004).

\section{Práticas de SI}

No contexto da filosofia grega antiga, as práticas de si constituíam um conjunto de exercícios (askesis) físicos e espirituais mediante os quais era possível ao sujeito atingir, por meio de rigorosa disciplina um modo de vida caracterizado pela liberdade plena. A prática cotidiana de tais exercícios contemplavam duas modalidades distintas e complementares, a física e a espiritual, porque visavam promover a plena ascese do indivíduo (HADOT, 2004). Como resultado prático, tais exercícios inspirados principalmente nos 
filósofos cínicos e estoicos promoveriam uma conversão radical do indivíduo, modificando seu modo de pensar e agir em relação a si mesmo e aos outros. Deste modo, o treinamento físico e o espiritual diário constituiriam um processo cujo resultado seria essa ascese ou uma transformação do indivíduo.

Tanto a resistência física quanto a perseverança espiritual decorrente da realização constante das práticas de si permitiriam ao indivíduo a obtenção e o domínio de dois princípios éticos, a autarquia e a apatia. Ambos os princípios constituem virtudes necessárias tanto para o domínio de si mesmo diante das vicissitudes e intempéries da vida, quanto para a prática da indiferença diante das coisas externas, tais como ações alheias que promovam atribulações no espírito do indivíduo (REALE, 1994).

O conceito de askesis em Foucault (2006) também implica na necessidade da execução diária, disciplina e determinada dos referidos exercícios, com a meta da busca pela ascensão. A constância na realização de tais práticas lograria ao indivíduo a possibilidade de autotransformar-se de tal modo que poderia estabelecer consigo mesmo uma relação mais livre e plena. Isso porque, os referidos exercícios físicos e espirituais diários não visam o autoconhecimento, mas o cultivo de si mesmo; trata-se, portanto de uma descoberta de novos modos de vida que habitam dentro de nós e que são exteriorizados (FOUCAULT, 2012b).

Numa rápida digressão para o campo educacional, podemos dizer que a sistemática realização de tais exercícios por parte de sujeitos educadores é importante porque faz que eles se defrontem com aspectos consideráveis de si mesmos que, não obstante, lhes eram desconhecidos. Ao possibilitar a si mesmo a confrontação com seus valores e preconceitos, o modo de viver do indivíduo, seu ethos, é significativamente alterado. Ao reinventar a si mesmo, antigas questões podem ser vislumbradas mediante perspectivas diferentes. As mudanças que acarretamos em nós mesmos também afetam nossas relações com os outros na medida em que deixamos de meramente assumir as convenções sociais e preconceitos como verdades absolutas para, em vez disso, considerá-las apenas como elementos de práticas instituídas, aos quais podemos opor resistência (PAGNI, 2011).

Para fins de delimitação, abordaremos somente uma das práticas de si, a parrhesía, porque a mesma está diretamente relacionada ao tema da franqueza e que, conforme acreditamos, contempla alguns aspectos importantes de alguns episódios da primeira temporada do seriado analisado. Desse modo, é necessário destacar que na parrhesía, temos a sugestão segundo a qual transformar a si mesmo, entre outras atribuições, "[...] implica na obrigação de dizer a verdade sobre si” (FOUCAULT, 2004, p. 321).

Abordaremos a noção de parrhesía na seção seguinte.

\section{A PARRHESía}

Na perspectiva filosófica grega antiga, mais do que dizer a verdade é preciso vivenciar a verdade. Isso significa que, assumir uma postura veraz diante de si mesmo e dos outros implica em riscos significativos. O parresiasta é alguém que, mesmo ciente dos riscos inerentes que corre ao proferir verdades, ainda assim as diz. Ao agir assim, coerente com a 
veracidade vivida, o sujeito que opta por dizer a verdade corre riscos de agressão, exílio, punições, injustiças, calúnias e até morte, perpetradas por indivíduos que preferiam o ocultamento da verdade, lisonjas ou mentiras.

Etimologicamente, parrhesiazesthai significa dizer tudo - de pan (tudo) e rhema (o que é dito). Aquele que usa a parrhesia, o parrhesiastes, é alguém que diz tudo o que tem em mente: ele não esconde nada, mas abre seu coração e sua mente completamente para outras pessoas através de seu discurso. Na parrhesia, presume-se que o falante dê um relato completo e exato do que tem em mente, de modo que a audiência seja capaz de compreender exatamente o que aquele que fala pensa. A palavra parrhesia então se refere a um tipo de relação entre o falante e o que ele diz. Pois na parrhesia o falante torna manifestamente claro e óbvio que o que ele diz é a sua própria opinião. E ele faz isso evitando qualquer tipo de forma retórica que pudesse velar o que ele pensa. Ao invés disso, o parrhesiastes usa as palavras e formas de expressão mais diretas que ele puder encontrar. Enquanto a retórica mune o orador com dispositivos técnicos para ajudá-lo a prevalecer sobre as mentes de sua audiência (independentemente da própria opinião do retórico concernente ao que ele diz), na parrhesia, o parrhesiastes age sobre a mente das outras pessoas mostrando a elas, tão diretamente quanto possível, o que ele realmente acredita (FOUCAULT, 2013, p. 4).

$\mathrm{Na}$ atualidade cotidiana comum, viver como um parresiasta não incorre nos temerários riscos de outrora que, por exemplo, um filósofo podia padecer diante de um vaidoso e enfurecido tirano, contrariado pela fala franca proferida. Entretanto, ainda há riscos. Por exemplo, alguém que diz a verdade pode ser demitido do emprego ou ser preterido por um bajulador que, imerecidamente, irá ocupar um cargo hierarquicamente melhor. Alguns relacionamentos e amizades também não sobrevivem à convivência com a dura verdade da realidade, preferindo a companhia de agradáveis e fantasiosas inverdades.

$\mathrm{Na}$ docência, por exemplo, torna-se cada vez mais comum a nítida preferência discente por silenciosas e injustificáveis notas altas em detrimento de críticas salutares e honestas (ainda que acompanhadas por notas mais modestas, embora igualmente aprovativas). Em geral, enquanto o primeiro tipo de docente é benquisto, o outro que incorre no segundo tipo de atribuição de nota ou conceito corre seriamente o risco de ser vilipendiado pela classe. É mais ou menos como a distinção entre dois amigos: um que lhe adverte sobre os seus erros e outro que é conivente com suas faltas.

Nessa perspectiva, é interessante observar que Foucault (2004, p. 343) indica um aspecto educativo relevante da parrhesía, quando afirma que: "[...] a verdade não está dentro do indivíduo, mas no logoi, os ensinamentos dos professores. O indivíduo memoriza aquilo que ouviu, convertendo as afirmações que ouve em normas de conduta".

Todavia, para o parresiasta não há alternativa entre dizer ou não dizer a verdade. Isso porque o falar franco é um ato de coragem diante do perigo. Disso podemos extrair que a principal característica da parrhesía é que dizer a verdade é um dever (FOUCAULT, 2013). Em outras palavras, a parrhesía também implica na "[...] coragem da verdade daquele que fala e corre o risco de dizer, a despeito de tudo, toda a verdade que ele pensa, mas é também a coragem do interlocutor que aceita receber como verdadeira a verdade ofensiva que ele escuta" (FOUCAULT, 2010, p. 14). 


\title{
AS SÉRIES TELEVISIVAS
}

Nas últimas cinco décadas, o advento de um novo fenômeno televisivo modificou consideravelmente a relação das pessoas com seus aparelhos televisivos. A partir da década de 1980, com o surgimento das séries televisivas, ocorreu uma progressiva transformação na forma mediante a qual as pessoas assistem TV. Primeiro, com a paulatina inserção através das TVs a cabo e, depois, com a internet e os aparelhos de DVDs, os seriados ganharam cada vez mais diversidade temática para suprir demandas cada vez maiores de públicos distintos. Assim, as séries televisivas se diversificaram continuamente para oferecer mais opções para nichos de consumidores com características, faixas etárias e interesses diferentes (SILVA, 2014).

\begin{abstract}
Nesse período, vimos se formar uma geração de espectadores capazes e interessados em assistir séries pela internet, através tanto de sistemas de transmissão em streaming, simultaneamente à exibição nos países de origem, quanto de download, via torrent, disponibilizados em sites e fóruns especializados. Além disso, circula na rede uma ampla gama de material exclusivo, oferecido pelos canais, e que vão desde promos, trailers e entrevistas, até expansões do mundo narrativo em websódios, blogs ou sites de personagens. Junto a esse processo, vêm sendo desenvolvidas diversas estratégias para estimular o espectador a comentar nas redes sociais durante a exibição dos episódios, como a presença da hashtag da série no canto da tela, ou mesmo a participação de membros da equipe e dos atores comentando com os seguidores no Twitter sobre o desenrolar da narrativa (SILVA, 2014, p. 246).
\end{abstract}

Nesse contexto é preciso diferenciar dois tipos básicos de séries de TV, os sitcoms e os seriados. Enquanto os episódios de sitcom têm uma estrutura mais simples em todos os aspectos (trama, personagens, diálogos, cenários etc.), pendem para os temas de humor ou situações cômicas e duram em média trinta minutos, os seriados são mais complexos, têm duração mais longa, por volta de uma hora, e privilegia temas com narrativas dramáticas. Outra característica relevante é que os episódios cômicos podem ser assistidos de forma independente entre si; já as histórias dramáticas demandam por parte do telespectador uma atenção sequencial ao enredo conectivo que os episódios estabelecem entre si e entre uma temporada e outra (PINHEIRO; BARTH; NUNES, 2016). Em virtude da delimitação proposta aqui, trataremos somente do segundo tipo de séries de TV: o seriado.

No seriado, o grau de realismo conferido aos personagens também pode contribuir para propiciar ao público uma confortável sensação de conhecer aquilo que é apresentado nas imagens. Ainda que nada seja real, os eventos da vida privada, profissional e social dos protagonistas devem aparentar verdadeiros. Isso porque: "No mundo das séries, a verdade surge sempre através das imagens: imagens da atualidade que a TV despeja, ou imagens índices que confundem [...]" (JOST, 2012, p. 32).

Desse modo, é preciso destacar que, mesmo quando o gênero do seriado é ambientado numa época, país ou contexto profissional diferentes daqueles do telespectador, o fator determinante para a aceitação por parte do público é a sua familiaridade com os enredos plenos de dramas humanos e a identificação com os protagonistas e suas relações interpessoais 
com outros personagens. O fato de os protagonistas pensarem e agirem, sob muitos aspectos, da mesma forma que o telespectador na sua vida cotidiana contribui para gerar um grau de identificação que é necessário para a continuidade do interesse pela trama ficcional.

Nesse novo contexto, é importante notar que o realismo das séries norte-americanas, entre outros fatores, constitui um forte apelo para os telespectadores que se identificam, sob muitos aspectos, com os dramas vivenciados pelos personagens principais: "O que seduz o telespectador não é, portanto, encontrar a cópia exata do nosso mundo, mas, sim, e sobretudo, um modo de narração, um discurso, com o qual ele está habituado" (JOST, 2012, p. 42).

\section{O Seriado The Good Doctor E A nOÇÃo de ParRHEsía}

Embora o presente estudo não trate especificamente de questões sobre ensino de filosofia ou de filosofia da educação, consideramos adequado justificar nossa escolha de articulação entre um tema filosófico e educacional e um elemento da cultura pop, no caso, os seriados. Desse modo, convém dizer que compartilhamos da perspectiva de Gallo (2012) que sustenta que é lícita a utilização de recursos não-filosóficos para o ensino de temas filosóficos. A ideia não é fazer que tais elementos substituam ou simplifiquem o teor complexo das teorias filosóficas ou educacionais, mas tão-somente facultar aos estudantes alguns recursos que possibilitem uma mediação que favoreça sua aprendizagem, que possibilite a introdução a temas teóricos mais complexos e estimule um posterior aprofundamento no estudo dos mesmos. Tal perspectiva, de certo modo, também é compartilhada por Rodrigo (2009) que apoia o uso de recursos didáticos não-convencionais para promover aulas mais interessantes e contextualizadas com a realidade dos estudantes. Cada docente deve construir o arsenal de apoio, a partir de seus interesses, experiências, conhecimentos e sensibilidade acerca das necessidades educacionais de seus estudantes. No presente caso, optamos pelo uso ou articulação dos seriados com um tema filosófico e educacional, visto que "[...] o arsenal, 'o saco de utilidades' é aquilo que o professor tem à mão para 'compor' a sua aula, a cada momento e segundo as circunstâncias" (GALLO, 2012, p. 151).

Assim, o protagonista do seriado norte-americano escolhido, The Good Doctor, é um jovem médico, Shaun Murphy, que tem conhecimentos e habilidades profissionais extraordinárias. A dramaticidade conferida ao personagem principal reside na sua condição peculiar que o faz padecer de alguns problemas relacionados ao âmbito dos transtornos do espectro autista. No seu caso especificamente, como um jovem médico portador da Síndrome de Savant, os problemas decorrem principalmente da dificuldade de convívio e interação social com seus colegas e pacientes que testemunham sucessivas demonstrações contrastantes entre talentos formidáveis e limitações discrepantes. Na trama da primeira temporada da série há uma ênfase nos conflitos entre Shaun e seus colegas de profissão. Tal ênfase está centrada principalmente na singular característica de falar sempre a verdade. Desse modo, é essa linha temática da franqueza que iremos articular com a noção foucaultiana de parrhesía.

O final do primeiro episódio da primeira temporada do seriado é emblemático para exemplificar o tipo de franqueza que caracteriza o personagem principal, Shaun Murphy. 
Depois de lidar com uma situação complexa, auxiliando uma criança acidentada no saguão de um aeroporto, o jovem médico consegue com bastante ressalva, ser admitido no conceituado Hospital San Jose St. Bonaventure. Assim, ele passa a integrar a equipe de médicos residentes do cirurgião-chefe Dr. Neil Melendez, contra a vontade do mesmo. Como represália, o trabalho que Melendez faz Shaun executar durante a cirurgia de um paciente, o de apenas aspirar as secreções, não é considerado apropriado para um médico com a sua formação e difere das funções atribuídas aos demais residentes (Ep. 01, Comida Queimada).

- É um bom rapaz. E é óbvio que é inteligente. Mas seu lugar não é aqui. Enquanto for da minha equipe, isso é tudo que você vai fazer: aspirar. (Melendez). - Eu vi muitos cirurgiões na escola de medicina. Você é muito melhor que eles. Eu tenho muito a aprender com o senhor. O senhor é muito arrogante. Acha que isso ajuda a ser um bom cirurgião? Isso não te magoa como pessoa? Vale a pena? (Shaun). (THE GOOD DOCTOR, Temp. 1, Ep. 01, 2017).

Todo o final do diálogo entre Melendez e Shaun é entremeado por cortes na cena que mostram as expressões de espanto por parte dos demais membros da equipe médica. $\mathrm{O}$ próprio Melendez não responde a qualquer das indagações e seu semblante também indica uma mescla de perplexidade e curiosidade diante daquela inaudita e ingênua afronta ao cargo que ele representa e ao poder hierárquico que ele exerce no hospital. Essa é a tônica que norteia boa parte da temporada inicial de The Good Doctor: a estranheza das pessoas diante dos questionamentos e dizeres francos de Shaun para todos aqueles que o cercam. No caso do diálogo transcrito, é preciso ressaltar que Shaun elogia seu chefe, realmente pensa que o mesmo tem as qualidades que ele admira. Não se trata de uma tentativa desesperada de agradar (Ep. 01, Comida Queimada).

Esse ponto é importante destacar porque a parrhesía tem como seus dois adversários principais a retórica e a lisonja. Enquanto a retórica é considerada como um adversário técnico em virtude dos diversos recursos que disponibiliza ao orador para o ocultamento da verdade, a lisonja é considerada como um adversário moral porque nitidamente assume uma pseudo posição de inferioridade diante do outro para fins de manipulá-lo mediante elogios inverídicos. Essa atitude é vista como um abuso moral em relação ao outro porque o indivíduo bajulador conscientemente esconde suas reais emoções, opiniões e interesses para tentar manipular seu interlocutor (FOUCAULT, 2006). Obviamente, esse não é o caso de Shaun que, ao inquerir sucessivamente seu chefe, correu seriamente o risco de agravar ainda mais a sua já delicada situação de médico residente recém-chegado na instituição hospitalar. De qualquer modo, nessa acepção, podemos admitir que a atitude de Shaun pode servir para exemplificar aquilo que Foucault (2010) explica quando diz que o retórico admite o uso da mentira e hipocrisia, mas o parresiasta não.

No episódio seguinte, como punição por ter chegado atrasado no hospital, Shaun é designado para realizar um trabalho que, geralmente, os demais médicos não fazem porque está mais associado com a rotina de trabalho dos enfermeiros. Eventualmente, quando os médicos são designados para essa função mais basilar seu trabalho é bastante protocolar: não se aprofundam nos casos dos pacientes, não examinam, não solicitam exames, não fazem diagnoses e, na maioria dos casos, simplesmente assinam as autorizações necessárias 
para que possam sair do hospital e ir para suas casas. Como o jovem médico protagonista é sistemático e apegado a regras e padrões, ele sempre consulta o regimento do hospital e tenta seguir à risca os protocolos recomendados. Assim, ele faz com os pacientes aquilo que os outros médicos não fazem: consultas, exames, acompanhamentos etc. Numa das cenas mais inusitadas, quando comparamos com a realidade da relação médico-paciente, Shaun revisa os exames de uma jovem paciente e vai até a sua residência, durante a madrugada, para alertar os pais da mesma sobre o risco de morte que a mesma corria. Inicialmente, tal atitude foi vista com muita suspeita pelos familiares da moça que, inclusive, afirmaram que a presença de Shaun naquele horário era incômoda. Nesse episódio, Shaun agiu conforme as regras institucionais determinavam ao oferecer o melhor de si como profissional e, também, como ser humano, ao fazer aquilo que sua consciência indicava como a atitude mais correta a ser praticada - ainda que de madrugada e fora do hospital. Tal atitude exemplifica aquilo que Foucault (2004) designa como necessário para ser o seu próprio diretor de consciência (Ep. 02, Monte Rushmore).

Já no sexto episódio, temos um dado importante para a presente discussão. Um fato que evidencia que nenhum dos personagens do seriado pode ser considerado como um genuíno parresiasta. Após um ser informado a respeito de algumas circunstâncias do procedimento pré-operatório de uma paciente, efetuado pela médica residente Dra. Claire Browne, o Dr. Glassman estabelece o seguinte diálogo com ela acerca do óbito da referida paciente (Ep. 06, Não é Falso):

- Eu ainda não contei para ela (Browne).

- E nem vai contar. Você cometeu um erro. Se envolveu demais no caso e eu não vou deixar você falar com a família e com ninguém mais fora desse hospital. Estamos entendidos? (Glassman). (THE GOOD DOCTOR, Temp. 1, Ep. 06, 2018).

O que fica evidente é que embora o Dr. Glassman, na maioria das vezes, atue caracteristicamente como alguém que fala com franqueza, esta não é sua atitude ampla e sistemática. No exemplo anterior, para proteger sua funcionária e colega, o médico ordena que a mesma silencie a verdade. A despeito da vontade dela de dizer aos familiares que seu erro contribuiu para que a ente querida deles viesse a falecer. (Ep. 06, Não é Falso).

É importante notar que, a partir da metade da primeira temporada, embora o preconceito por parte da equipe do hospital, paciente e familiares, Shaun já começa a angariar, ainda que veladamente em conversas isoladas, como na afirmação do Dr. Melendez para a Dra. Claire, um pouco de respaldo por seus êxitos no trabalho e de reconhecimento em relação aos seus conhecimentos e habilidades excepcionais. Inclusive, uma das situações explícitas de preconceito em relação à sua condição se dá por parte dos pais de uma paciente autista que relutam em deixar que seu filho seja atendido por um médico aparentemente na mesma condição de seu filho (Ep. 07, 22 Passos). Afirmamos que é aparentemente, porque a condição de Shaun como autista e savantista não é padrão, pois nem todo indivíduo considerado com portador do transtorno do espectro autista tem a Síndrome de Savant.

Todavia, o tema do erro médico aparece novamente, num episódio subsequente, dessa vez, protagonizado por Shaun, cuja atitude inadvertidamente difere da atitude de 
seu mentor. Assim, enquanto Shaun não consegue se esquivar de proferir verdades, Glassman relativiza a verdade: escolhe quando vai omitir a verdade ou falar francamente e com quem. O jovem médico, por sua vez, é quase a personificação da seguinte definição foucaultiana da franqueza: "Na parrhesía só pode haver verdade. Onde não houver verdade não há franco-falar. A parrhesía é a transmissão nua, por assim dizer, da própria verdade" (FOUCAULT, 2010, p. 343).

Durante uma operação cirúrgica, com dois de seus colegas médicos, Melendez e Jared, Shaun observa que o primeiro, que também é seu chefe, cometeu um erro ao perfurar o brônquio de uma paciente. Diante dessa observação do jovem médico, o colega questionado indaga qual foi seu suposto erro. Sem titubear, ele responde: "-A lesão. Foi culpa sua". Mediante tal constatação, enquanto o interlocutor fica calado, o outro médico demonstra um semblante de espanto pelo fato de a verdade ter sido dita de forma tão natural (Ep. 13, Sete Motivos). Aqui é importante lembrar que muitos erros profissionais graves, que prejudicam, lesionam ou matam são, em muitos ramos profissionais, silenciados em prol de um sistemático corporativismo. Infelizmente, na contemporaneidade, o que é considerada anômala é a ação ética daquele indivíduo que, em vez de silenciar diante do erro e da injustiça, profere a verdade sob os mais diversos riscos: desde a hostilidade e marginalização profissional até a demissão.

No caso de Shaun, sua inquietação decorre do fato de ter que seguir regras sem, no entanto, saber se isso é algo correto a se fazer. Assim, ele procura seu mentor, Dr. Glassman, relata o ocorrido e indaga:

- Eu preciso saber se preciso dar queixa do Dr. Melendez. (Shaun).

- O Dr. Melendez fez isso? (Glassman).

- O protocolo é bem claro: eu preciso dar queixa. Mas eu já vi como o Jared é tratado. O Dr. Melendez vai me tratar mal se eu der queixa? (Shaun).

- Não deveria, é obvio, mas como a natureza humana ... (Glassman).

- Natureza humana ...? (Shaun).

- Shaun, sabe de uma coisa? Você deve tomar essa decisão sozinho. Aliás, você deve tomar toda decisão sozinho daqui para frente. Foi isso que combinamos, não é? (Glassman). (THE GOOD DOCTOR, Temp. 1, Ep. 13, 2018).

Esse diálogo travado entre Shaun e Glassman ilustra de forma bastante instrutiva o fato que, em alguns pontos cruciais, o segundo personagem atua como um mestre parresiasta. Isto é, ele aconselha o jovem aprendiz a não depender de seus ensinamentos. Por mais difícil que isso seja para ambos. Como afirma Foucault (2006), a franqueza não visa beneficiar aquele que fala, mas sim ajudar aquele que ouve o discurso verdadeiro a encontrar o seu próprio autodomínio.

Nessa perspectiva, precisamos lembrar que a parrhesía não pode ser definida como uma forma de ensinamento, nos moldes tradicionais, como uma transmissão de conteúdos previamente definidos. Entretanto, na relação entre um mestre e seu pupilo, podemos ter configurada uma situação na qual a figura mais velha age em relação ao mais jovem de forma parresiasta. Tal situação educativa é mais pessoal do que aquela que é contemplada e criticada no cenário coletivizado das instituições escolares contemporâneas. 
Não vejo onde está o mal na prática de alguém que, em um dado jogo de verdade, sabendo mais do que um outro, lhe diz o que é preciso fazer, ensina-lhe, transmite-lhe um saber, comunica-lhe técnicas; o problema é de preferência saber como será possível evitar nessas práticas - nas quais o poder não pode deixar de ser exercido e não é ruim em si mesmo - os efeitos de dominação que farão com que um garoto seja submetido à autoridade arbitrária e inútil de um professor primário; um estudante, à tutela de um professor autoritário etc. Acredito que é preciso colocar esse problema em termos de regras de direito, de técnicas racionais de governo e de êthos, de prática de si e de liberdade (FOUCAULT, 2012b, p. 278).

No entanto, a relação entre Shaun e o Dr. Aaron Glassman, que também é o diretor-geral do hospital do seriado, pode servir para exemplificar um aspecto filosófico e educativo interessante da parrhesía. Inicialmente, Glassman atua como uma espécie de tutor e conselheiro para Shaun. Todavia, como o passar do tempo, a série mostra que o médico mais velho que, sob certo aspecto, age inicialmente de forma paternal em relação ao jovem médico, reavalia sua atitude. Isso é descrito de forma gradativa nos episódios em que Glassman tenta incentivar a independência emocional de Shaun, ao afastar-se cada vez mais dele (Ep. 13, Sete Motivos). Essa atitude aparentemente insensível por parte de Glassman é explicada posteriormente com a revelação da sua grave condição clínica que, por ser inoperável, faz que tenha somente mais alguns meses de vida (Ep. 17, Sorria). Diante da proximidade da morte, essa lucidez de Glassman em relação a Shaun pode ter decorrido justamente da consciência de que ele precisava, como um bom mestre parresiasta, preparar seu pupilo para que este não dependesse mais dele e nem de ninguém (Ep. 18, Mais). Trata-se, portanto, de um compromisso ético com o outro: usar da franqueza, a verdade dita de modo abrupto e simples, para inspirar o indivíduo a tornar-se sujeito de sua própria vida.

\section{CONSIDERAÇõeS FINAIS}

O que enfatizamos até o presente momento é que o tema da franqueza, do ato de falar a verdade abertamente pode ser ilustrado de modo bastante interessante a partir de algumas cenas e diálogos do seriado The Good Doctor. Como foi possível observar mediante os exemplos destacados, embora o discurso verdadeiro seja algo aparentemente simples de ser expresso, na prática das relações interpessoais, isso não acontece. No seriado, em muitas situações a verdade deixa de ser dita ou é camuflada para atender a fins pessoais. Por sua vez, na teoria foucaultiana, temos a proposta de uma figura, o mestre parresiasta, que deve sempre falar a verdade em conformidade com a sua própria consciência.

Como a verdade nua sempre escandaliza uma sociedade acostumada com mentiras e estratégias de ocultamento de ideias e emoções autênticas, o parresiasta precisa aprender as práticas de si, isto é, técnicas que o auxiliem a cuidar de si mesmo e a viver em conformidade com essa ética pessoal de franqueza (PAGNI, 2012). Para tanto, uma das principais práticas de si é a parrhesía, aqui destacada por estar diretamente vinculada ao tema da veridicção. Tal como afirma Foucault (2010, p. 148): “[...] é essa nova ética da relação verbal com o outro que está designada na noção fundamental de parrhesía". Trata-se de uma 
direção de consciência, uma orientação geral para nortear nossa relação discursiva com os outros a partir da franqueza plena que, nesse contexto, significa abertura de coração e de pensamento. Tal abertura tem, na prática, a seguinte implicação: o sujeito é impelido a proferir um discurso franco não apenas porque esta é a sua vontade, mas porque ele acredita que seja necessário, útil e verdadeiro (FOUCAULT, 2010).

Como foi possível notar, não há no seriado The Good Doctor um parresiasta autêntico, nos moldes foucaultianos. Isso porque, a franqueza do Dr. Shaun, o personagem principal, decorre de sua condição singular de autista e savantista. Já o personagem que em alguns momentos foi descrito como uma espécie de tutor do jovem médico, o Dr. Glassman, não se destaca pelo falar franco. Sua fala só é verdadeira em alguns momentos cruciais, o que difere da concepção foucaultiana. Assim, é importante notar que nenhum dos personagens do seriado é parresiasta. O contínuo e sistemático discurso verdadeiro proferido por Shaun decorre de uma condição orgânica atípica, isto é, a sua franqueza não provém do aprendizado de uma prática de si, mas de sua condição autista. E o autismo não pode, nos termos foucaultianos, ser considerado como uma força produtora da parrhesía ou de qualquer técnica.

Considerada por Foucault (2010) como uma das principais práticas de si, a parrhesía, organizada em torno do princípio de dizer a verdade, permite que a veridicção produza na alma do indivíduo os efeitos de transformação. Em outras palavras, "a arte da existência e o discurso verdadeiro" permitem: "[...] A emergência da verdadeira vida no princípio e na forma do dizer-a-verdade (dizer a verdade aos outros, a si mesmo, sobre si mesmo e dizer a verdade sobre os outros), verdadeira vida e jogo do dizer-a-verdade [...]" (FOUCAULT, 2010, p. 142). Dessa forma, a conversão radical ocorre como uma mudança substancial na percepção da própria vida, compreendida agora como uma obra de arte. Por isso, a importância da franqueza para a possibilidade de viver a vida como obra bela ou estética da existência.

\section{REFERÊNCIAS}

BARNETT, Kristine. Brilhante: a inspiradora história de uma mãe e seu filho gênio e autista. Trad. José Rubens Siqueira. Rio de Janeiro: Zahar: 2013.

FOUCAULT, Michel. Tecnologias de si (1982). Verve, São Paulo, n. 6, p. 321-360, 2004.

FOUCAULT, Michel. A hermenêutica do sujeito. Trad. Márcio Alves da Fonseca e Salma Tannus Muchail. São Paulo: Martins Fontes, 2006.

FOUCAULT, Michel. A Coragem da verdade: O governo de si e dos outros II: curso no Collège de France (1983-1984). Trad. de Eduardo Brandão. São Paulo: Martins Fontes, 2010.

FOUCAULT, Michel. A ética do cuidado de si como prática de liberdade. In: Ditos e Escritos - volume V: Ética, sexualidade e política. Trad. Elisa Monteiro e Inês Altran Dourado Barbosa. Rio de Janeiro: Forense Universitária, 2012b, p. 258-280. 
FOUCAULT, Michel. Uma estética da existência. In: Ditos e Escritos - volume V: Ética, sexualidade e política. Trad. Elisa Monteiro e Inês Altran Dourado Barbosa. Rio de Janeiro: Forense Universitária, 2012a, p. 281-293.

FOUCAULT, Michel. 1 ${ }^{\mathrm{a}}$. Conferência: o significado da palavra parrhesia (1983). Trad. Aldo Dinucci, Rodrigo Brito e Valter Duarte. Prometeus: filosofia em revista, Sergipe, ano 6, n. 13, p. 3-12, 2013.

GALLO, Silvio. Metodologia do ensino de filosofia: uma didática para o ensino médio. São Paulo: Papirus, 2012.

HADOT, Pierre. O que é filosofia antiga. Trad. Dion Davi Macedo. São Paulo: Loyola, 2004.

JOST, François. Do que as séries americanas são sintoma? Trad. Elizabeth B. Duarte e Vanessa Curvello. Porto Alegre: Sulina, 2012.

MUCHAIL, Salma Tannus. Foucault, simplesmente. São Paulo: Loyola, 2004.

MUCHAIL, Salma Tannus. Foucault, mestre do cuidado. São Paulo: Loyola, 2011.

PAGNI, Pedro Ângelo. Entre a modernidade educacional e o modernismo: um ensaio sobre a possibilidade de uma Filosofia da Educação como arte da superfície. In: SEVERINO, A. J.; ALMEIDA, C. R. S.; M. A. LORIERI (Orgs.). Perspectivas da Filosofia da Educação. São Paulo: Cortez Editora, 2011, p. 150-166.

PAGNI, Pedro Ângelo. Matizes filosófico-educacionais da formação humana e os desafios da arte de viver. In: PAGNI, Pedro A.; BUENO, Sinésio F.; GELAMO, Rodrigo P. (Orgs.). Biopolítica, arte de viver e educação. São Paulo: Cultura Acadêmica, 2012, p. 35-50.

PINHEIRO, Cristiano Max Pereira; BARTH, Maurício; NUNES, Raona. Televisão e Serialidade: Formatos, Distribuição e Consumo. Cadernos de Comunicação, [S.1.], v. 20, n. 2, p. 1-19, ago. 2016. ISSN 2316-882X. Disponível em: https://periodicos.ufsm.br/ccomunicacao/article/view/22925. Acesso em: 20 fev. 2020.

REALE, GIOVANNI. História da filosofia antiga. Trad. Marcelo Perine. São Paulo: Loyola, 1994.

RODRIGO. Lídia Maria. Filosofia em sala de aula: teoria e prática para o Ensino Médio. Campinas: Autores Associados, 2009.

ROGERS, Sally J.; DAWSON, Geraldine; VISMARA, Laurie A. Autismo: compreender e agir em família. Lisboa: Lidel, 2015. 
SILVA, Marcel Vieira Barreto. Cultura das séries: forma, contexto e consumo de ficção seriada na contemporaneidade. Galáxia (São Paulo, Online), n. 27, p. 241-252, jun. 2014.

SIQUEIRA, Thomaz Décio Abdala; GALVÃO, Drielly da Silva; MARQUES JUNIOR, Nelzo Ronaldo de Paula Cabra; REUSE, Jociani Andrade. Síndrome de Savant: compreendendo sua evolução e tratamento através da literatura. BIUS - Boletim Informativo Unimotrisaúde em Sociogerontologia, Manaus, v. 12, n. 5, p. 1-12, set. 2019.

THE GOOD DOCTOR (O Bom Doutor) - 1a ${ }^{\text {a }}$ Temporada. In: Superflix, 2019. Disponível em: http://www.superflix.net/temporada/assistir-serie-the-good-doctor-1a-temporada-dublado-online-legendado-8/. Acesso em: 13 nov. 2019.

THE GOOD DOCTOR: O Bom Doutor (TV Series 2017- ). In: Internet Movie Database - IMDB, 2019. Disponível em: https://www.imdb.com/title/tt6470478/?ref_=fn_al tt 1 . Acesso em: 13 dez. 2019.

VEIGA-NETO, Alfredo. Foucault e a Educação. Belo Horizonte: Autêntica, 2011.

ZORZETTO, Ricardo. O cérebro no autismo. Rev. Pesquisa FAPESP, São Paulo, 2011, n. 184, v. 43, p. 16-23, jun. 2011.

\section{DADOS DOS AUTORES}

\section{Fernanda Antônia Barbosa da Mota}

Doutorado em Educação pela Universidade Federal do Piauí. Teresina/PI-Brasil. Professora no Departamento de Fundamentos da Educação da Universidade Federal do Piauí. Teresina/PI- Brasil. fabmota13@yahoo.com.br

\section{Heraldo Aparecido Silva}

Doutorado em Filosofia pela Universidade Federal de São Carlos. São Carlos/SP-Brasil. Professor no Programa de Pós-Graduação em Filosofia da Universidade Federal do Piauí. Teresina/PI- Brasil. heraldokf@yahoo.com.br

Submetido em:11-5-2020

Aceito em: 17-11-2020 